\section{IJ§ER}

ISSN: 2149-5939
International Journal of Social Sciences and Education Research

Online, http://dergipark.gov.tr/ijsser

Volume: 3(3), 2017

\title{
Kadın ve erkek üniversite öğrencilerinin bilişötesi öğrenme stratejile- rinin karşılaştırılması
}

\author{
Comparison of metacognitive learning strategies of female and male university \\ students
}

Bülent Ağbuğa1

Received Date: 02 / 02 / 2017

Accepted Date: 31 / 05 / 2017

$\ddot{O} z$

Bu araștırmanın amacı, kadın ve erkek üniversite öğrencilerinin kullandıkları bilișötesi öğrenme stratejilerine ilişkin ne düzeyde bilgi sahibi olduklarını belirlemek ve karşılaştırmaktır. Araştırmaya 2015-2016 eğitim ve öğretim yllında Ĕ̈itim ( $n=99)$, Spor Bilimleri $(n=97)$, ve Mühendislik Fakültelerinde $(n=100)$ ögrenim görmekte olan toplam 296 (167 erkek ve 133 kadın) ögrrenci katılmıştır. Araştırmaya katılan üniversite ögrrencilerinin bilişötesi ögrenme stratejilerinin belirlenmesinde Namlu (2004) tarafindan geliștirilen Bilişötesi Öğrenme Stratejileri Ölçeği kullanılmıştır. Verilerin normal dă̆ılım gösterip göstermediğine Kolmogrov-Smirnov analizi ile bakılmış ve normal dağllım göstermediği tespit edilmiştir $(p<.005)$. Bu yüzden, elde edilen verilerin analizi için Mann Whitney U testi istatistik analizleri kullanılmıștır. Bununla birlikte açımlayıcı istatistik analizide yapılmıștır. Araștırma sonuсu üniversite ögrencilerinin bilişötesi öğrenme stratejilerini orta seviyede kullandıkları bulunmuştur. Bu sonuç daha önce yapılan araştırmaların sonuçlarıyla benzerlik göstermektedir. Bununla birlikte, cinsiyetler arası yapılan karşılaştırma sonucunda "biliş ötesi toplam", "planlama" ve "denetleme" puanlarının erkekler lehine istatistiksel olarak anlamlı düzeyde farklılık taşıdı̆̆ $(p<0,05)$, "örgütleme" ile "değerlendirme” puanlarının istatistiksel olarak anlamlı düzeyde farklılık göstermediği tespit edilmiştir $(p>0,05)$. Bu bulgu önceki araștırmaların sonuçlarından farklıdır. Bu sonucun ortaya çıkmasının temelinde yatan nedenlerin başında daha önce yapılan araştırmaların sadece beden ĕgitimi ögretmenliği bölümü ögrencileri üzerine odaklanmaları olabilir. Halbuki, bu araștırmada farklı fakültedeki kadın ve erkek ögrenciler katılımcı olarak katılmıştır. Bu bulgu kadın ve erkek üniversite ögrencilerinin farklı biliş̈tesi öğrenme stratejilerini kullanabildiklerini ve hatta farklı fakültelerde ve coğrafik bölgede yer alan üniversitelerde ögrenim gören ögrencilerin farklı bilişötesi ögrenme stratejileri kullanabileceklerini göstermektedir. Bu yüzden, gelecekte yapllacak araștırmalar farkll fakültelerdeki, üniversitelerdeki ve hatta farklı bölgelerdeki ve farklı sosyo-ekonomik seviyede olan ögrencilerin bilişötesi ögrrenme stratejilerini cinsiyet değişkeni açısından karşılaştırmalıdır.

Anahtar sözcükler: Üniversite ögrencileri, Bilişötesi ögrenme, Cinsiyet

\begin{abstract}
The purpose of this study was to investigate the metacognitive learning strategies of the university students in different faculties. The study group included a total of 296 (167 male and 133 female) students; Education Faculty students $(n=99)$. Sport Science Faculty students $(n=97)$ and Enginering Faculty students $(n=100)$. For determination of metacognitive learning strategies of university students, Metacognitive Learning Strategies Scale developing by Namlu (2004) was used. the Kolmogorov-Smirnov test was applied to test for a normal distribution and the result found that the data distribution was not normal $(p<.005)$. Therefore, Mann-Whitney U statistical analysis were performed. Descriptive analysis was also performed. It has been found that university students used metacognitive learning strategies at medium level. This result is consistent with the previous research results. In addition to this, this study also found statistically significant difference between male and female students in the total score of metacognitive, organization and controlling scores $(p<0.05)$ in the favor of male students. However, no statistically difference in the planning and evaluating scores were found ( $p>0.05$ ). This result is different from previous research. It was concluded that this significant difference happened because of previous research participants were only included physical education and sport teaching department students. However, students from different faculties were participated in this study. This study shows that male and female students use different metacognitive learning strategies so future research should compare both male and female students' metacognitive learning strategies from different faculties, universities and even from different geographical and sociocultural areas.
\end{abstract}

Keywords: University Students, Metacognitive Learning, Gender

\footnotetext{
${ }^{1}$ Prof. Dr., Pamukkale University, School of Sport Sciences, Denizli/TURKEY, bakboga@pau.edu.tr
} 
Ağbuğa, B. (2017).Kadın ve erkek üniversite öğrencilerinin bilişötesi öğrenme stratejilerinin karşılaştırılması.

International Journal of Social Sciences and Education Research. 3(3), 783-791.

\section{Giriş}

Hızla değiş̧en yaşam koşullarına uyum sağlayabilmek, en kısa sürede en fazla bilgi ve beceriyi edinebilmek ve bu bilgi ve beceriyi kullanabilmek için sadece farkında olmak (biliş) yeterli olmamakta hangi öğrenme stratejilerini nasıl kullandığının da (bilişötesi) bilinmesi gerekmektedir. Bilişötesi, öğrenenin kendi biliş sistemi, yapısı, çalışması hakkındaki bilgisidir (Namlu, 2004). Bununla birlikte bilişötesi kavramı, öğrenenin neyi bilip neyi bilmediğini bilmesini ve kişinin düşüncesinin değişik yönlerinin farkındalığını ifade etmektedir (Namlu, 2004). Öğrenenin neyi, nasıl öğrenebildiği; nasıl hatırlayıp kendini nasıl güdülediği; öğrenmesini nasıl kontrol ettiği ve yönlendirdiği bilişötesi öğrenme olarak da kabul edilebilir (Weinstein \& Mayer, 1983).

Öğrenmenin kalitesi öğretim programlarının kalitesi (içeriği, öğretim yöntemleri, öğretmenin vasıfları ve öğretim malzemeleri vb.) ile birlikte öğrenenin kalitesinin (bilişötesi düşünme düzeyi, güdülenmesi, çabası, zekası, yeteneği vb.) birleşkesidir. Öğrenenin öğrenmesini kolaylaştıran yöntemlerden her biri öğrenme stratejisi olarak tanımlanabilir (Özer, 2002). Öğrenme stratejileri, "öğrenme sürecinde öğrenenin kendisini yönlendirebilmesi ve bu yönde özerk ve bağımsız öğrenme becerileri geliştirme yolları" olarak da tanımlanabilir (Namlu, 2004, s. 125). Klasik öğrenmede belleğe yerleştirme ve geri getirme gibi “bilişsel öğrenme stratejileri” yer alırken, bilgiyi işleyerek kalıcı biçimde öğrenmesi de modern öğrenme de "bilişötesi öğrenme stratejilerinin" devreye girmesini gerektirir. Bilişötesi öğrenme stratejileri, öğrenenin kendi bilişini kontrol etmesini (merkezde toplama, sıraya dizme, planlama ve değerlendirme vb.) kullanarak öğrenme sürecini düzenlemelerine olanak sağlayan süreçlerdir (Namlu, 2004). Sınıf ortamında bilgilerin akı1da kalıcı şekilde öğrenilmesi için bilişötesi öğrenme stratejileri öğrencileri plan yapmaya, öğrenmelerini kontrol etmeye, öğrenmelerini ayarlamaya ve değerlendirmeye itmektedir.

Literatürde bilişötesi öğrenme stratejilerine yönelik ve bu stratejilerin farklı alt boyutlarının ele alınmış olduğu araştırmalar bulunmaktadır. Örneğin, Brezin (1980) bilisötesi öğrenme stratejilerini planlama, seçici dikkat, analiz, yeniden gözden geçirme ve değerlendirme olarak beş grupta sinıflarken, Blakey ve Spence (1990) bilisötesi öğrenme stratejilerini planlama, denetleme ve değerlendirme olmak üzere üç grupta toplamıştır. Bilişötesi stratejilerin alt yapılarını belirlemek ve literatürle karşılaştırmasını yapmak için Namlu (2004) bilişötesi öğrenme stratejilerine yönelik bir ölçme aracı geliştirmiş ve bunun sonucunda bilişötesi öğrenme stratejilerini oluşturan alt boyutları analiz ederek ortaya koymuştur. Araştırması sonucunda bilişötesi öğrenme stratejilerini dört alt boyuta ayırmıştır: Planlama, örgütleme, denetleme ve değerlendirme.

Günümüze kadar yapılan çalışmalarda eğitim fakülteleri bölümlerinde öğrenim gören üniversite öğrencilerinin bilişötesi öğrenme stratejileri incelenmiştir. Kahyaoğlu ve Daban (2007) okul öncesi öğretmen adaylarının biliş ötesi öğrenme stratejilerinden örgütleme, denetleme ve değerlendirmenin planlamadan daha yüksek olduğunu belirtmiş̧tir. Beden eğitimi ve spor yüksekokulu öğrencileri üzerinde yapılan diğer araştırmalarda öğrencilerin bilişötesi öğrenme stratejilerini orta seviyede kullandıkları; (Kılıç ve Öncü, 2014; Kılıç, Cihan, \& Öncü, 2015) ve öğrenim gördükleri bölümlere göre de farklılık gösterdiği tespit edilmiştir (Çağlayan, Şirin, \& Yıldız, 2008). Kartal, Kayacan ve Selvi (2013) tarafından yapılan araştırmada farklı öğretmenlik bölümlerde öğrenim görmekte olan öğretmen adaylarının bilişötesi öğrenme stratejilerini kullanma düzeylerinin çeşitli değişkenlere göre incelemiş ve bölümler arası anlamlı farklılık göstermediklerini tespit etmişlerdir. Halbuki, literatüre bakıldığında farklı fakültelerde öğrenim gören kadın ve erkek öğrencilerin bilişötesi öğrenim stratejilerini ve alt boyutlarını inceleyen araştırmaların eksikliğinden söz edilebilir. Özellikle farklı fakültelerde okuyan kadın ve erkek üniversite öğrencilerinin, akademik 
Ağbuğa, B. (2017). Comparison of metacognitive learning strategies of female and male university students. International Journal of Social Sciences and Education Research. 3(3), 783-791.

başarıyı belirlemede önemli olan bilişötesi öğrenme stratejilerini hangi seviyede ve hangi alt boyutlarını kullandıkları bir soru işareti olarak ön plana çıkmaktadır. Bu yüzden, bu araştırmanın temel amac1, farklı fakültelerde öğrenim gören üniversite öğrencilerinin bilişötesi öğrenim stratejilerini incelemektir.

\section{Yöntem}

\subsection{Araştırmanın modeli}

$\mathrm{Bu}$ araştırmada, kadın ve erkek üniversite öğrencilerinin bilişötesi öğrenme stratejilerinin ne düzeyde oldukları ve bu öğrencilerinin bilişötesi öğrenme stratejileri karşılaştırıldığı için tarama modeli kullanılmıştır. Tarama modeli, bir konuya ya da olaya ilişkin katılımcıların görüşlerinin ya da ilgi, beceri, yetenek ve tutum gibi özelliklerinin belirlenmesi olarak tanımlanmaktadır (Fraenkel \& Wallen, 2006). Bu yöntemde var olan durum olduğu gibi gösterilmektedir.

\subsection{Katıllimcular}

Araştırmanın evrenini 2015-2016 eğitim ve öğretim yılında Pamukkale Üniversitesi’nde öğrenim görmekte olan üniversite öğrencileri oluşturmaktadır. Araştırmanın örneklemi ise Pamukkale Üniversitesi'nde öğrenim gören eğitim fakültesi öğrencisi (31 kadın ve 69 erkek), spor bilimleri fakültesi öğrencisi (48 kadın ve 51 erkek) ve mühendislik fakültesi öğrencisi (54 kadın ve 47 erkek) olmak üzere toplam 300 öğrenciden oluşmuştur.

\subsection{Veri toplama aract}

Araştırmada Namlu (2004) tarafından geliştirilen Bilişötesi Öğrenme Stratejileri Ölçeği ve Kişisel Bilgi Formu kullanılmıştır. Bilişötesi Öğrenme Stratejileri Ölçeği dörtlü Likert türünde bir ölçek olup, Ölçekte bulunan maddeler (ters ifade edilmiş olan bir, iki ve beş numaralı maddeler hariç) 4 puandan 1 puana doğru "her zaman" "sık sık", "bazen" ve "hiçbir zaman" biçiminde tasarlanmıştır. Ölçeğin geçerlilik ve güvenilirlik çalışmaları sonunda ölçek "planlama stratejileri "örgütleme stratejileri”, "denetleme stratejileri" ve "değerlendirme stratejileri” olarak adlandırılan 4 faktörden ve 21 maddeden meydana gelmiştir. Ölçekten elde edilebilecek en düşük puan 21 en yüksek puan ise 84'dür (Demir, 2013; Namlu, 2004).

\subsection{Verilerin toplanmast}

Araştırmacılar tarafından gerekli izinlerin alınmasını takiben araştırmaya katılacak gönüllü öğrencilere ders saatlerinden hemen önce ölçek verilmiştir. Ölçeğin doldurulmasından önce, araştırmanın amacı ile ilgili gerekli açıklamalar yapılarak ölçeğin doldurulması hakkında bilgilere de yer verilmiştir. Araştırmacı tarafından toplanan veriler, kontrol edilerek eksik doldurulanlar araştırma dişında tutulmuştur.

\subsection{Verilerin analizi}

Ölçek verileri fakültelere göre karşılaştırılmadan önce verilerin normal dağılıma uygun olup olmadığg incelenmiştir. Yapılan inceleme sonucunda, verilerin normal dağılıma uygun olmadığ tespit edilmiştir. Bu nedenle fakültelere göre ölçek verilerini karşılaştırmak için non parametrik testlerden olan Mann Whitney U testleri kullanılmıştır. Ayrıca betimleyici istatistik analizi yapılmıştır. Yapılan testlerde anlamlılık düzeyi $\mathrm{p}<0,05$ olarak kabul edilmiştir. 
Ağbuğa, B. (2017).Kadın ve erkek üniversite öğrencilerinin bilişötesi öğrenme stratejilerinin karşılaştırılması. International Journal of Social Sciences and Education Research. 3(3), 783-791.

\section{Bulgular}

İstatiksel analize geçmeden önce verilerin normal dağılıma uygun olup olamadığını belirlemek için tek örneklem Kolmogorov Smirnov testi uygulanmış ve verilerin normal dağılım göstermediği tespit edilmiştir (Tablo 1). Bu yüzden, bilişötesi alt boyutlarına ve genel toplama ait puan ortalamalarının fakülte durumuna göre farklılaşıp farklılaşmadığ ilişkin Man-Whitney U testleri yapıldı (Tablo 2).

Tablo 1. Kolmogorov-Smirnov ve açımlayıcı istatistik analizleri sonucu

\begin{tabular}{lccccc}
\hline Parametreler & Planlama & Örgütleme & Denetleme & Değerlendirme & $\begin{array}{c}\text { Bilişötesi } \\
\text { Toplam }\end{array}$ \\
\hline $\mathbf{n}$ & 300 & 300 & 300 & 300 & 300 \\
$\mathbf{X}$ & 2,309 & 2,608 & 2,772 & 2,373 & 2,517 \\
$\mathbf{S s}$ &, 327 &, 683 &, 634 &, 551 &, 393 \\
$\quad \begin{array}{l}\text { Kolmogo- } \\
\quad \text { rov- Smir- }\end{array}$ &, 114 &, 080 &, 107 &, 104 &, 036 \\
$\quad$ nov Z & & & & & \\
$\boldsymbol{p}$ &, $000^{*}$ &, $000^{*}$ &, $000^{*}$ &, $000^{*}$ &, $000^{*}$ \\
\hline$* 0,01$ & & & & &
\end{tabular}

Tablo 2. Araştırma grubunun bilişötesi toplam puanına İlişkin Mann Whitney U Test Sonuçları

\begin{tabular}{lcccccc}
\hline Boyutlar & Cinsiyet & N & $\begin{array}{c}\text { Sira Orta- } \\
\text { laması }\end{array}$ & $\begin{array}{c}\text { Sira Top- } \\
\text { lamı }\end{array}$ & U & $p$ \\
\hline Planlama & Erkek & 167 & 162,52 & 27141,0 & 9098,0 &, $006^{* *}$ \\
& Kadın & 133 & 135,41 & 18009,0 & & \\
Örgütleme & Erkek & 167 & 156,03 & 26056,5 & 10182,5 &, 215 \\
& Kadın & 133 & 143,56 & 19093,5 & & \\
Denetleme & Erkek & 167 & 160,94 & 26877,0 & 9362,0 &, $019^{* *}$ \\
& Kadın & 133 & 137,39 & 18273,0 & & \\
Değerlendirme & Erkek & 167 & 147,78 & 24679,0 & 10651,0 &, 538 \\
& Kadın & 133 & 153,92 & 20471,0 & & \\
Bilişötesi Top- & Erkek & 167 & 159,87 & 26699,0 & 9540,0 &, $036^{* *}$ \\
lam & & & & & & \\
& Kadın & 133 & 138,73 & 18451,0 & & \\
\hline
\end{tabular}

$* * p<0,05$

Tablo 2'yi incelediğimizde bilişötesi öğrenme stratejilerinin planlama, denetleme ve toplam puanlarının arasında istatistiki yönden anlamlı farkın kadın öğrencilere göre erkek öğrencilerin yüksek puanından kaynaklandığg görülmektedir. 
Ağbuğa, B. (2017). Comparison of metacognitive learning strategies of female and male university students.

International Journal of Social Sciences and Education Research. 3(3), 783-791.

\section{Sonuç ve tartışma}

$\mathrm{Bu}$ araştırmanın sonuçlarından biri katılımcıların orta düzeyde bilişötesi öğrenme stratejilerini kullandıklarının tespit edilmesi olmuştur. Bu sonuç önceki araştırmalar ile benzerlik göstermektedir (İflazoğlu \& Bal, 2010; Kılıç \& Öncü, 2014). Örneğin, Kılıç ve Öncü (2014) beden eğitimi öğretmenliği öğrencileri üzerinde yaptığı araştırmada katılımcıların orta seviyede bilişötesi öğrenme stratejilerini kullandıklarını tespit etmiştir.

Araştırmaya katılan öğrencilerin biliş ötesi genel puanları ile planlama ve denetleme puanlarının kadın ve erkek üniversite öğrencileri arasında istatistiksel olarak anlamlı düzeyde farklılık gösterdiği, buna karşılık kadın ve erkek öğrencilerin örgütlenme ve değerlendirme alt boyutlarına ilişkin puanlarının istatistiksel açıdan anlamlı farklılık göstermediği belirlenmiştir. Bulunan cinsiyetler arası farklı1ık ve hatta erkekler lehine olması yapılan diğer araştırmalar ile çelişmektedir. Örneğin, Baykara (2011) yaptığı araştırmada İngilizce öğretmen adaylarının, özyeterlik algısı ile bilişötesi öğrenme stratejileri arasında anlamlı bir ilişkinin olup olmadığı ve adayların öz-yeterlik algıları ile bilişötesi öğrenme stratejilerinin cinsiyet ve sınıf düzeylerine göre farklılığına bakmıştır. Baykara (2011) bilişötesi öğrenme stratejilerinin cinsiyete göre değişmediğini bulmuştur. Bununla birlikte, Okçu ve Kahyaoğlu (2007) ilköğretim öğretmenlerinin bilişötesi öğrenme stratejilerinden planlama, örgütleme, denetleme ve değerlendirme stratejilerini incelemiştir. Araştırma sonucunda öğretmenlerin örgütleme ve denetleme biliş ötesi stratejileri ortalama puanlarının planlama ve değerlendirme stratejilerinden daha yüksek olduğu ve cinsiyet, kıdem, branş ve görev değişkenlerine göre bilişötesi öğrenme stratejileri arasında anlamlı bir farkın olmadığı tespit edilmiştir. Öte yandan birçok araştırma kadınların bilişötesi öğrenme stratejileri ortalamalarının erkeklere göre daha yüksek olduğunu belirtmektedir (İflazoğlu \& Tümkaya, 2008; Kartal vd, 2013; Kılıç vd, 2015). Örneğin, Kılıç vd. (2015) yaptıkları araştırmada beden eğitimi öğretmenliği bölümü öğrencilerinin bilişötesi öğrenme stratejilerini incelemiş ve cinsiyet değişkenine göre "planlama", "örgütleme" ve "denetleme" alt boyutlarında kadın katılımcılar lehine anlamlı farklılıkların olduğunu bulmuşlardır. Öte yandan, yalnız Kılıç ve Öncü (2014) araştırmalarında bilişötesi öğrenme stratejilerinin cinsiyet değişkenine göre erkek katılımcılar lehine farklılaştığını tespit etmişlerdir. Bu sonuç yaptığımız araştırmanın sonucu ile benzerlik göstermektedir.

$\mathrm{Bu}$ farklı sonuçların ortaya çıkmasının temelinde yaptığımız araştırmanın katılımcıları arasında beden eğitimi öğretmenliği öğrencileri ile birlikte farklı fakültelerdeki öğrencilerinde olması olabilir. Özellikle farklı fakültedeki erkek öğrencilerin derslerinden başarılı olabilmeleri için planlama ve denetleme öğrenim stratejileri başta olmak üzere hemen hemen bütün bilişsel öğrenme stratejilerini daha fazla kullanmalarına ihtiyaç duymaları olabilir.

Kadın ve erkek öğrencilerin bilişötesi öğrenme alt boyutlarına ilişkin bazı özelliklerinin farkl1lık göstermesinin bir nedeni olarak, toplumun cinsiyetler üzerindeki (erkek egemenliği) beklentileri doğrultusunda mezuniyet sonrası iyi bir işe girebilmenin ilk şartı gözüken akademik başarıyı elde etmek için daha fazla biliş ötesi öğrenme stratejileri kullanmak zorunda kalmaları düşünülebilir.

$\mathrm{Bu}$ araştırmanın sonucu literatürdeki çoğu araştırmaların sonucundan farklı çıkmıştır. Bu farklılık bu konu üzerine daha fazla araştırmaların yapılması gerekliliğini ortaya çıkarmaktadır. Bundan dolayı, bu araştırmanın başka üniversitelerin farklı fakülte öğrencileri üzerinde tekrar yapılmasını tavsiye etmekteyiz. Böylece yapılacak yeni araştırmalar bulunan sonucun ne kadar geçerli olduğunu tespit edecektir. 
Ağbuğa, B. (2017).Kadın ve erkek üniversite öğrencilerinin bilişötesi öğrenme stratejilerinin karşılaştırılması. International Journal of Social Sciences and Education Research. 3(3), 783-791.

Bu araştırmanın sonucunda, özellikle kadın öğrencilerin eksik kalan bilişötesi öğrenme stratejilerinin öğretim elemanları tarafından belirlenip, bu eksikleri derslerini kullanarak tamamlamalarına yardım etmeleri gerektiği görülmektedir. Hatta Özcan'ın (2007) önerdiği gibi biliş ötesi öğrenme stratejilerinin öğretmen adaylarına ayrı bir ders olarak verilmesi de düşünülebilir. $\mathrm{Bu}$ sayede üniversite öğrencileri hem akademik yaşamın içinde hem de dışında yaşamı daha da kolaylaştıracak bilişötesi öğrenme stratejilerine sahip olabileceklerdir.

\section{Kaynakça}

Baykara, K. (2011). Öğretmen adaylarının bilişötesi öğrenme stratejileri ile öğretmen yeterlik algıları üzerine bir çalışma. Hacettepe Üniversitesi Eğitim Fakültesi Dergisi, 40, 80-92.

Blakey, E., \& Spence, S. (1990). Developing Metacognition. Syracuse, NY: ERIC Information Center Resources.

Brezin, M. J. (1980). Cognitive monitoring: From Learning Theory to Instructional Applications. Educational Communicatins and Technology Journal, 28, 227-242.

Çağlayan, H. S., Şirin, E. F., \& Yıldız, Ö. (2008). Beden Eğitimi ve Spor Yüksekokulu Öğrencilerinin Genel Öğrenme Stratejilerini Kullanma Düzeylerinin Bazı Değişkenlere Göre İncelenmesi. TSA, 12(2), 45-62.

Demir, Ö. (2013). Öğretmen Adaylarının Ders Çalışma Sırasında Bilişsel Farkındalık Becerilerini Kullanma Düzeylerinin İncelenmesi: Nitel Bir Çalışma. Hacettepe Üniversitesi Eğitim Fakültesi Dergisi, 44, 133-148.

Fraenkel, J.R., \& Wallen, N.E. (2006). How to design and evaluate research in education. New York: McGraw-Hill.

İflazoğlu, S. A., \& Bal, A. P. (2010). Matematik ve sınıf öğretmenliği bölümlerinde okuyan öğrencilerin öğrenme stratejilerinin bazı sosyo-demografik özellikler açısından incelenmesi. Ege Ĕ̈itim Dergisi, 11(2): 1-19.

İflazoğlu, S. A., \& Tümkaya, S. (2008). Öğretmen adaylarının öğrenme stratejileri ile sosyo-demografik özellikler ve akademik başarıları arasındaki ilişkinin incelenmesi. Ege Eğitim Dergisi, 9(1), 1-22.

Kahyaoğlu, M., \& Daban, Ş. (2007). Okul Öncesi Öğretmen Adaylarının Biliş ötesi Öğrenme Stratejileri. 16.Ulusal Eğitim Bilimleri Kongresi Gaziosmanpaşa Üniversitesi/Tokat.

Kartal, T., Kayacan, K., \& Selvi, M. (2013). Öğretmen Adaylarının Bilimsel Tutum ve Bilişötesi Öğrenme Stratejilerine İlişsin Farkındalık Düzeylerinin Çoklu Değişkenler Açısından İncelenmesi. The Journal of Academic Social Science Studies, 6(1), 913-939.

Kılıç, S., K, \& Öncü, E. (2014). Beden Eğitimi ve Spor Yüksekokulu Öğrencilerinin Bilişötesi Öğrenme Stratejileri ve Akademik Öz-Yeterlilikleri. Spor ve Performans Araştırmaları Dergisi, 5, 13-22.

Kılıç, S. K., Cihan, H., \& Öncü, E. (2015). Beden Eğitimi Öğretmen Adaylarının Bilişötesi Öğrenme Stratejileri, Akademik Öz-Yeterlikleri ve Öğretmenlik Mesleğine Yönelik Tutumları. Hacettepe Spor Bilimleri Dergisi, 26, 77-89.

Namlu, A. G. (2004). Bilişötesi Öğrenme Stratejileri Ölçme Aracının Geliştirilmesi: Geçerlilik ve Güvenirlik Çalışması. Sosyal Bilimler Dergisi, 2, 123-136. 
Ağbuğa, B. (2017). Comparison of metacognitive learning strategies of female and male university students. International Journal of Social Sciences and Education Research. 3(3), 783-791.

Okçu, V., \& Kahyaoğlu, M. (2007). İlköğretim Öğretmenlerinin Biliş Ötesi Öğrenme Stratejilerin Belirlenmesi. Süleyman Demirel Üniversitesi Sosyal Bilimler Enstitüsü Dergisi, 6, 129-146.

Özer, B. (2002). İlköğretim ve Ortaöğretim Okullarının Eğitim Programlarında Öğrenme Stratejileri. Eğitim Bilimleri ve Uygulama, 1(1), 17-32.

Özcan, Z. Ç. (2007). Sinıf Öğretmenlerinin Derslerinde Biliş̧ Üstü Beceri Geliştiren Stratejileri Kullanma Özelliklerinin Incelenmesi. Marmara Eğitim Bilimleri Enstitüsü Doktora Tezi. İstanbul.

Weinstein, C. E., \& Mayer, R.E. (1983). The Teaching of Learning Strategies. Innovation Abstracts, 5(32). 
Ağbuğa, B. (2017).Kadın ve erkek üniversite öğrencilerinin bilişötesi öğrenme stratejilerinin karşılaştırılması. International Journal of Social Sciences and Education Research. 3(3), 783-791.

\section{Extended Abstract in English}

In order to be able to adapt to rapidly changing living conditions and to acquire the most knowledge and skills in the shortest time, it is not only enough to use this knowledge and skills, but also it is necessary to know how to use learning strategies. Metacognition is the knowledge of the learner's own cognitive system, structure and work (Namlu, 2004). The notion of metacognition, however, expresses what the learner knows and the awareness of the different aspects of one's thinking (Namlu, 2004). What and how learners can learn; how he/she remember; how he/she guides him/herself; how he/she can control learning can be regarded as metacognitive learning (Weinstein \& Mayer, 1983). In the classroom environment, metacognitive learning strategies leads students to plan, to control, to arrange and to evaluate their learning. Importantly, metacognitive learning strategies can enable students to arrange their thinking, to become independent learners, and to improve their school experiences. To Today, metacognitive learning strategies of university students studying in different departments of education faculties have been examined. Kahyaoğlu and Daban (2007) stated that preschool teacher candidates have higher levels of organizing, supervising and evaluating of cognitive learning strategies than planning strategy. Other studies found that students of physical education and sport department used metacognitive learning strategies in the middle level (Kılıç \& Öncü, 2014; Kılıç, Cihan, \& Öncü, 2015) and these students used different learning strategies according to their departments they have studied in (Çağlayan, Şirin, \& Yıldız, 2008). However, the application of the metacognitive learning strategies have not been extensively examined between male and female university students.

Therefore, the purpose of this study was to investigate the metacognitive learning strategies of male and female university students in different faculties. Specifically, the following research questions were addressed: (a) What metacognitive learning strategies do university students endorse? (b) Are there any differences between male and female university students' metacognitive learning strategies? The study group included a total of 296 students; Education Faculty students $(\mathrm{n}=99)$, Sport Science Faculty students $(\mathrm{n}=97)$ and Enginering Faculty students $(\mathrm{n}=100)$ in Pamukkale University (167 male and 133 female).

Students responded to questions regarding their age, gender, school and grade level. For determination of metacognitive learning strategies of university students, a 21 item "Metacognitive Learning Strategies Scale" developing by Namlu (2004) was used. They reflected organization, controlling, planning, and evaluating scores. Students rated each item on a 4-point scale, ranging from 1 (Never) to 4 (Always). Cronbach alpha value of the scale was 0,81 . A confirmatory factor analysis (CFA) was conducted on items measuing students' metacognitive learning strategies to test for the four types of strategies. The CFA was conducted using AMOS 5 (Analysis of Moment Structures). Namlu's (2004) study indicated there were four distinct metacognitive learning strategies represented in the data set. All indices $\left(\chi^{2} / d f=2.61, \mathrm{CFI}=.93, \mathrm{GFI}=0.93, \mathrm{NFI}=.90, \mathrm{TLI}=0.92, \mathrm{SRMR}=0.05\right.$ and RMSEA $\left.=.005\right)$ represent an acceptable fit. The Kolmogorov-Smirnov test was applied to test for a normal distribution and the result found that the data distribution was not normal $(p<.005)$. Therefore, Mann-Whitney $\mathrm{U}$ statistical analysis were performed. Descriptive analysis was also performed.

The results indicate that university students use metacognitive learning strategies at medium level. This result is consistent with the previous research results (Baykara, 2011; Kılıç, Cihan ve Öncü, 2015). In addition to this, this study also found statistically significant difference between male and female students in the total score of metacognitive, organization and controlling scores $(p<0.05)$ in the favor of male students. However, no statistically difference in the planning and evaluating scores were found $(p>0.05)$. This result is different from most previous research (e.g.,Baykara, 2011; Kılıç et al., 2014). For example, Baykara (2011) found no "Metacognitive 
Ağbuğa, B. (2017). Comparison of metacognitive learning strategies of female and male university students. International Journal of Social Sciences and Education Research. 3(3), 783-791.

Learning Strategies" difference between male and female prospective teachers. But, it is discovered that there is a positive difference on behalf of female prospective teachers' "organizational strategies", a subdivision of applied scale. On the other hand, this result consistent with K1lıç and Öncü (2014) study which indicate significant differences between metacognitive learning strategies and gender of the students. Male students were found to have higher metacognitive learning strategies scores. It is recommended that university students, especially female students, are assisted with the implementation of metacognitive strategies in the teaching and learning of their study areas. By providing enough information of metacognitive learning strategies to female university students, they will be better learner and close the gap between themselves and male classmates. 